\title{
Lyme Borreliosis Spirochetes and Spotted Fever Group Rickettsiae in Ixodid Ticks from Pianosa Island, Tuscany Archipelago, Italy
}

\author{
L. Tomassone, E. Grego, D. Auricchio, A. Iori, ${ }^{2}$ F. Giannini, ${ }^{3}$ and L. Rambozzi ${ }^{1}$
}

\begin{abstract}
A study on tick fauna and tick-borne pathogens was undertaken in Pianosa, an island in the Tuscany Archipelago that constitutes an important stopping and nesting point for migratory birds. Ticks were removed from feral cats and a few terrestrial birds, and host-seeking ticks were collected by dragging. A total of 89 ticks were found on animals: 57 Ixodes ventalloi Gil Collado, 1936 and 32 Ixodes acuminatus Neumann, 1901. Host-seeking ticks were 354 Hyalomma spp. larvae and 18 Hyalomma spp. adults, identified as Hyalomma marginatum C.L. Koch, 1844 $(n=11)$ and 7 Hyalomma detritum Schulze, $1919(n=7)$. A sample of adult ticks was subjected to molecular analyses to look for Rickettsia spp. and Borrelia burgdorferi sensu lato (s.1.). Sequence analysis of the 5S-23S intergenic spacer region and OspA gene of B. burgdorferi s.l.-positive samples showed the presence of Borrelia spielmanii $(n=3 ; 3.7 \%$, 95\% confidence interval [CI] $0.08-10.4)$ and Borrelia valaisiana $(n=13 ; 13.6 \%$, 95\% CI 7.0 23.0) in Ixodes ticks from cats and terrestrial birds. Ixodes spp. were also infected by Rickettsia helvetica $(n=19$; 23.4\%, 95\% CI 14.7-34.2). Finally, we detected Rickettsia aeschlimannii in 3 out of 12 host-seeking Hyalomma spp. adults tested (25\%, 95\% CI 5.5-57.2). Our study shows the presence of several tick-borne pathogens in Pianosa. Hyalomma spp. and Ixodes ticks other than I. ricinus seem to be involved in their epidemiological cycle, and birds could contribute to the pathogen dispersal along their migration routes. This is the first finding of B. spielmanii in Italy. We hypothesize the involvement of peridomestic rodents or hedgehogs in its maintenance in Pianosa.
\end{abstract}

Key Words: Pianosa island—Ixodes spp.—Hyalomma spp.—Borrelia spielmanii—Rickettsia aeschlimannii.

\section{Introduction}

$\mathbf{R}$ ICKETTSIAE OF THE SPOTTED FEVER GROUP (SFG) and spirochetes in the Borrelia burgdorferi sensu lato (s.l.) complex are emerging threats in Europe. Along with the rickettsiae and borreliae that have been recognized as pathogenic for decades, an increasing number of species are being discovered and identified as human pathogens (Labruna et al. 2011, Stanek and Reiter 2011). For example, Borrelia spielmanii was isolated in the first decade of the $21^{\text {st }}$ century in Lyme disease patients with erythema migrans (Fingerle et al. 2008). Among SFG rickettsiae, Rickettsia aeschlimannii was first characterized in Africa in 1997, but is now considered the causative agent of rickettsiosis in many areas inhabited by its tick vector Hyalomma spp. (Matsumoto et al. 2004).
Migratory birds could be partly responsible of the heterogeneous distribution of tick-borne pathogens in Europe, because they are considered responsible for the dissemination of ticks in their migration routes and are recognized reservoir hosts of some agents (Kjelland et al. 2010).

The island of Pianosa is an important stopping and nesting site for avian species because of its history, which has made it unspoiled and scarcely inhabited for many years. Within a project aiming at capturing feral cats, which constituted a threat for migrating birds, ticks were collected from the felines and from terrestrial birds. Moreover, hostseeking ticks were collected by dragging. Tick identification and molecular analyses were then undertaken to describe the tick fauna of Pianosa and the presence of tick-borne pathogens.

\footnotetext{
${ }^{1}$ Dipartimento di Produzioni Animali Epidemiologia ed Ecologia, Facoltà di Medicina Veterinaria, Università degli Studi di Torino, Grugliasco, Torino, Italy.

${ }^{2}$ Dipartimento di Sanità Pubblica e Malattie infettive, Università di Roma Sapienza, Roma, Italy.

${ }^{3}$ Parco Nazionale Arcipelago Toscano, Ufficio Conservazione della Biodiversità, Portoferraio, Livorno, Italy.
} 


\section{Materials and Methods}

\section{Study area}

The island of Pianosa (N $42^{\circ} 34^{\prime} 53^{\prime \prime}$, E $10^{\circ} 4^{\prime} 34^{\prime \prime}$ ) is part of Tuscany Archipelago in the Tyrrhenian Sea, Tuscany region, Italy. Pianosa has an area of $10.2 \mathrm{~km}^{2}$, is plain, and its highest point reaches about 30 meters above sea level. From 1858, it was the seat of an agricultural penal colony. For this reason, and thanks to the establishment of a National Park (Parco Nazionale dell'Arcipelago Toscano) in 1996-1997, Pianosa remained unspoiled by human presence and activities for many years. Since the closure of the prison in 1997, the island is almost uninhabited, and only daily guided tours are possible for tourists during the summer season.

The vegetation is characterized by typical Mediterranean species, such as junipers (Juniperus communis, J. oxycedrus and J. phoenicea), mastik trees (Pistacia lentiscus), rosemaries (Rosmarinus officinalis), cists (Cistus incanus, C. monspeliensis), myrtle (Myrtus communis), helichrysum (Helichrysum litoreum), and lavender (Lavandula stoechas) (Colom et al. 2004). The fauna are represented by small mammals, such as rodents, hedgehogs (Erinaceus europaeus), Kuhl's pipistrelles (Pipistrellus kuhlii), and wild hares (Lepus europaeus). The black rat (Rattus rattus), Norway rat (Rattus norvegicus), and house mouse (Mus musculus domesticus) were accidentally introduced to the island, and wild hares were introduced for hunting (Agnelli 1998, Angelici et al. 2009). Cats (Felis catus) live as wild predators; they were abandoned by humans after the closure of the penal colony and represent a threat for land and marine birds (seagulls and shearwaters in particular). The avifauna, both local and migratory, are abundant in Pianosa. Among others, colonies of Audouin's gull (Ichthyaetus audouinii), Cory's shearwater (Calonectris diomedea), Mediterranean shearwater (Puffinus yelkouan), and European shag (Phalacrocorax aristotelis desmarestii) are present. Moreover, a large population of pheasants (Phasianus colchicus) and red partridges (Alectoris rufa) inhabits the island, and several marine and terrestrial species spend their winter there.

\section{Tick collection}

Ticks were collected on vertebrate hosts and by dragging the vegetation, within the framework of the LIFE Natura Project LIFE04NAT/IT/000172, co-financed by European Union and region of Tuscany (2004-2007). One of the project aims was eliminating wild cats from the island by sterilizing and releasing them on the Elba Island.

Ticks were collected from trapped cats and from 3 terrestrial birds found dead/dying on the island footpaths-1 common pheasant (Phasianus colchicus), 1 red partridge (Alectoris rufa), and 1 water rail (Rallus aquaticus). Dragging was performed on the same transects used to trap wild cats, which were randomly chosen after dividing the island in 6 areas and considering existing footpaths. Four 1-km length transects per area were selected, and dragging was carried out by 2 operators, using a 1-square meter cotton cloth. The operators stopped at each 10 meters approximately to check the cloth for tick presence. Tick collection was performed in October, 2006 (on-the-host and host-seeking ticks collection), and August, 2007 (dragging only); sampling periods were chosen based on convenience (logistic support on the island by the personnel of LIFE Natura project). A total of 7 dragging transects were covered in October, 2006, and 24 in August, 2007. Arthropods were stored in $70 \%$ ethanol and subsequently identified using keys by Manilla (1998), Estrada-Peña et al. (2004), and Cringoli et al. (2005).

\section{Molecular analyses}

Tick DNA was extracted by using the QIAGEN DNeasy tissue kit (Qiagen $\mathrm{GmbH}$, Hilden, Germany). The infection by B. burgdorferi s.l. was investigated by a PCR protocol targeting a 337-bp fragment of the intergenic spacer (IGS) region included between genes coding for the $5 \mathrm{~S}$ and $23 \mathrm{~S}$ subunits of ribosomal RNA (Rijpkema et al. 1995). For better characterization, positive samples were submitted to the amplification of a 800 -bp fragment of the outer surface protein A (OspA) gene. In detail, $5 \mu \mathrm{L}$ of DNA extract were put in $25-\mu \mathrm{L}$ reactions containing 10X CoralLoad PCRBuffer PCR (Qiagen), $0.03 \mathrm{mM}$ concentrations of the forward primer OspAf (Grego et al. 2007; 5'ATGAAAAAATATTTATTGGGAATA-3') and of the reverse primer OspAr_gen (5'-ATTCTCCYTATTTYAAAGCG-3'), $200 \mu \mathrm{M}$ of deoxyribonucleotide triphosphates (dNTPs), and $1 \mathrm{U} /$ reaction of Taq DNA polymerase (Qiagen). Cycling conditions included denaturation at $94^{\circ} \mathrm{C}$ for $3 \mathrm{~min} ; 40$ cycles of $94^{\circ} \mathrm{C}$ for $1 \mathrm{~min}, 50^{\circ} \mathrm{C}$ for $1 \mathrm{~min}$, and $72^{\circ} \mathrm{C}$ for $1 \mathrm{~min}$; and a final extension at $72^{\circ} \mathrm{C}$ for $10 \mathrm{~min}$. DNA from Borrelia afzelii (Nancy strain) and B. garinii (BL3 strain) was used as positive controls in each PCR run. The OspA reverse primer was designed based on the alignment of $B$. burgdorferi s.l. reference sequences available on GenBank and the sequences database obtained from previous studies.

The presence of rickettsial DNA in ticks was investigated as described in Tomassone et al. (2010): a first PCR assay targeted the citrate synthase gene $(g l t A)$; positive samples were further tested to detect the ompA gene, specific for the SFG rickettsiae. In each PCR run, DNA from Rickettsia conorii was used as a positive control.

RNase- and DNase-free water and nucleic acid extracts from sure negative samples were used as negative controls to determine any possible cross-reactivity or contamination; 1 negative control every 5 field samples was included in each PCR run.

Amplified products were analyzed by electrophoresis in $2.5 \%$ agarose and visualized by staining with $0.1 \%$ ethidium bromide. Amplicons were purified using ExoSAP-IT PCR Clean-up Kit (GE Healthcare Limited, Chalfont, UK) and sent to an external service (Macrogen Inc., Amsterdam, The Netherlands) for automatic sequencing. Sequences were analyzed by Chromas 2.0 software (Technelysium, Helensvale, Australia) and submitted to BLAST (http://blast.ncbi.nlm.nih.gov/) to identify similarities to known sequences and, therefore, to classify pathogens at the species level.

Prevalence of tick species and PCR-positive results were calculated, with 95\% exact binomial confidence intervals $(95 \%$ CI), by using R software (R Development Core Team, 2008).

\section{Phylogenetic analysis}

Sequences obtained from positive samples were aligned with reference sequences available in GenBank using ClustalW (Thompson et al. 1997) and were imported into PAUP* (ver. 4.0b10; Swofford, 2003). The model of molecular evolution was estimated using a hierarchical likelihood ratio test approach and the Akaike information criterion (Akaike 1973) implemented in the computer program ModelTest ver. 3.7 
(Posada and Crandall 2001). The phylogenetic trees and the statistical support for clades were created using the Bayesian methods implemented in MrBayes (ver. 3.1.1; Ronquist and Huelsenbeck 2003). A Markov chain Monte Carlo search for 1,000,000 generations using 2 runs with 4 chains (temperature $=0.05$ ) was performed, and results were represented as a $50 \%$ majority rule consensus tree. The pairwise genetic distance comparisons were calculated by the Nei-Gojobori method (Nei and Gojobori 1986).

\section{Results}

A total of 426 ticks were collected during fieldwork. Onthe-host ticks were all adults $(n=89)$ : 57 Ixodes ventalloi Gil Collado, 1936, and 32 Ixodes acuminatus Neumann, 1901. Hostseeking ticks were 354 Hyalomma spp. larvae, which were identified at the genus level, and 18 Hyalomma spp. adults, namely Hyalomma marginatum C.L. Koch, $1844(n=11)$ and Hyalomma detritum Schulze, $1919(n=7)$ (Table 1). Eleven Hyalomma larvae were collected in October, 2006 (0.16 specimens per 100-meter dragging), while in August, 2007, we gathered 343 larvae (1.43 specimens /100 meters) and the 18 adults $(0.075 / 100$ meters $)$.

The PCR for B. burgdorferi s.l. and Rickettsia spp. detection was performed on 81 Ixodes spp. ticks. The Rickettsia spp. PCR assay was also carried out on 12 host-seeking Hyalomma spp. adults. The remaining Ixodes and Hyalomma specimens were kept in the laboratory as reference specimens.

Overall, 16 Ixodes spp. were positive to B. burgdorferi s.l. 5S23S IGS PCR (19.7\%; 95\% CI 11.7-30.1): 12 I. ventalloi, and 4 I. acuminatus. The sequences clustered into two clades defined by reference strains of B. spielmanii and Borrelia valaisiana (Fig. $1)$. The pairwise genetic distances varied from 0 to 0.034 among the B. spielmanii sequences and from 0 to 0.027 among the $B$. valaisiana sequences. Positive ticks were taken from 3 different cats and from the red partridge (B. spielmanii), water rail, and pheasant (B. valaisiana). Results are detailed in Table 1. The borrelia $O s p A$ gene could be amplified only from 9 Ixodes spp. positive to 5s-23s IGS. The dendrogram based on the $\operatorname{sp} p$ A gene (Fig. 2) showed that the B. valaisiana sequences belong to the subgroup I strain (Wang et al. 2000; Ryffel et al. 2003); the pairwise genetic distances varied from 0 to 0.023 . Only one $\operatorname{spA} B$. spielmanii sequence was obtained.

The Rickettsia gltA gene was detected in 20 Ixodes spp. (35.8\%; 95\% CI 25.5-47.2) collected from cats and terrestrial birds. Nine I. ventalloi and 10 I. acuminatus were found infected by Rickettsia helvetica, whereas Rickettsia sp. IRS3 was detected in $1 \mathrm{I}$. ventalloi from a cat. Positive ticks were collected from 8 different cats. Co-infection by B. valaisiana and $R$. helvetica was detected in 1 I. acuminatus from a cat and 1 I. ventalloi from the pheasant, whereas B. spielmanii was detected together with $R$. helvetica in $1 \mathrm{I}$. acuminatus collected on the red partridge. Finally, 3 out of the 12 adult host-seeking Hyalomma examined were positive to both $g l t A$ and OmpA rickettsial genes (25\%, 95\% CI 5.5-57.2), and Rickettsia aeschlimannii was identified.

\section{Discussion}

A variety of tick-borne zoonotic agents were detected in our study in Pianosa. B. spielmanii is reported for the first time in Italy. This spirochete is characterized by a focal distribution in Europe (Fingerle et al. 2008) and is considered to be more host specific than other B. burgdorferi s.l. genospecies, being

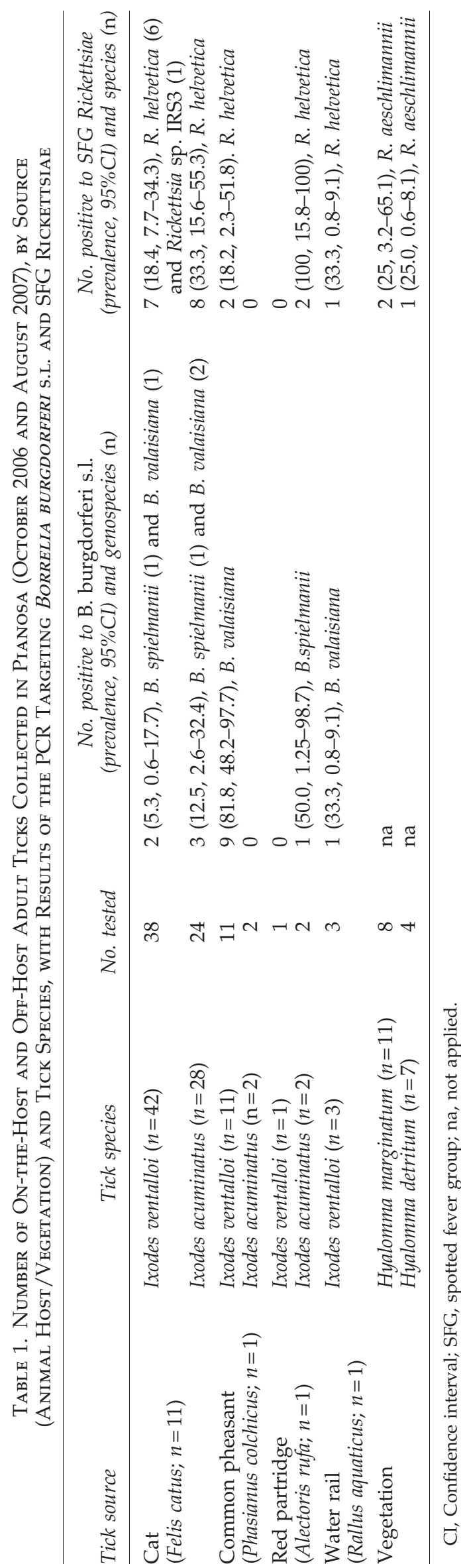




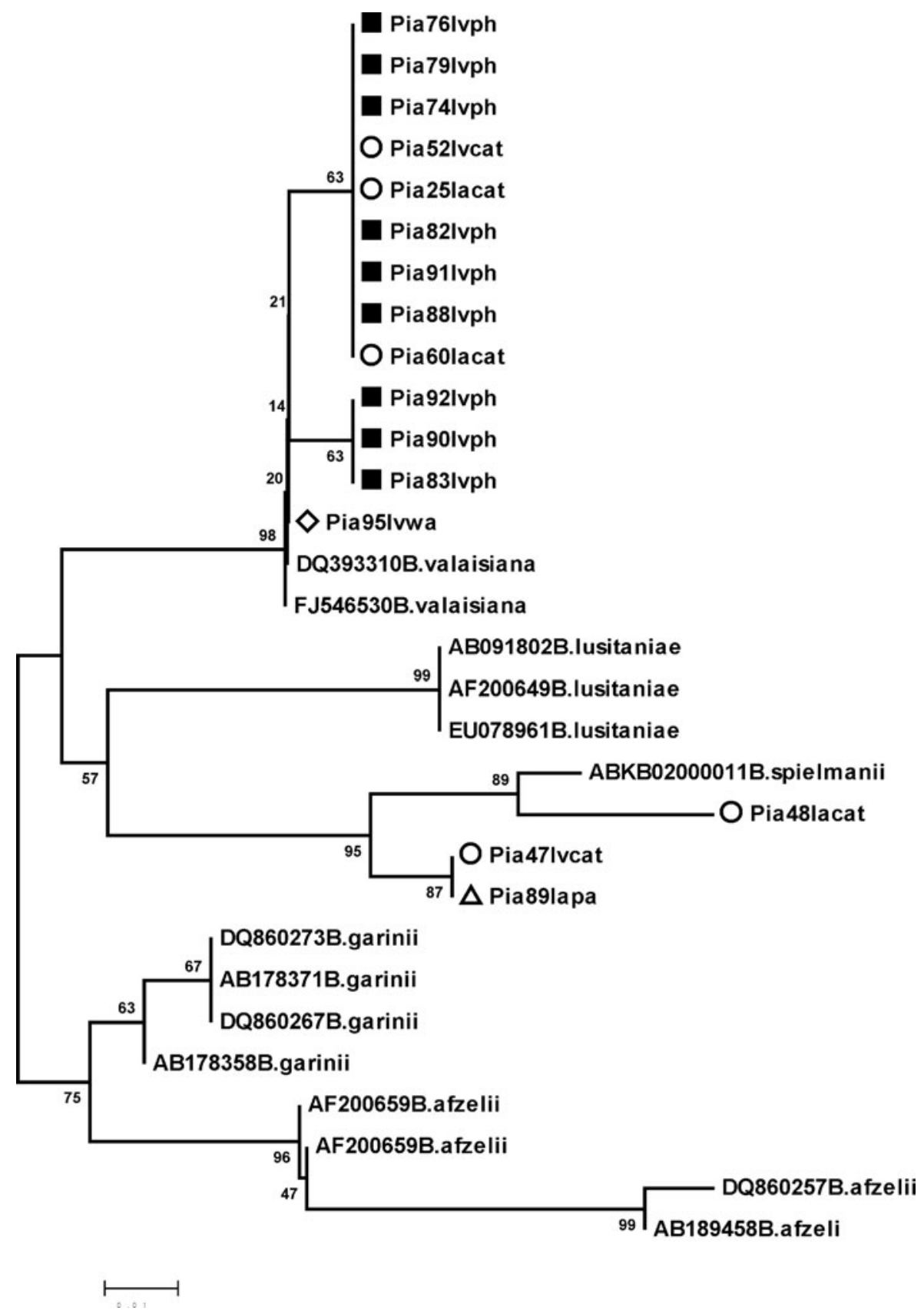

FIG. 1. Phylogenetic tree based on the 5S-23S intergenic spacer (IGS) of Pianosa B. burgdorferi s.l. sequences and National Center for Biotechnology Information (NCBI) reference sequences. Pianosa sequences are highlighted by a square (positive ticks from pheasants), a circle (from cats), a rhombus (from water rail), or a triangle (from red partridge). Iv, I. ventalloi; Ia, I.acuminatus; cat, tick collected on a cat; ph, on pheasant; wa, on water rail; pa, on partridge. Posterior probability values are reported below branches. Bar, 0.01 substitutions per site.

strictly associated with the garden dormouse (Eliomys quercinus; Richter et al. 2004). Dormice are not reported in Pianosa (Angelici et al. 2009); thus, we can hypothesize the maintenance of $B$. spielmanii by resident alternative hosts such as peridomestic rodents or hedgehogs. Indeed, mice (Apodemus sylvaticus, Apodemus flavicollis, M. musculus) and Norway rats were shown to be competent hosts for B. spielmanii, although being less efficient reservoirs than dormice (Richter et al. 2011). Moreover, Skuballa et al. (2007, 2012) detected B. spielmanii in tissues from E. europaeus and in Ixodes ricinus ticks subjected to xenodiagnostic experiments on hedgehogs, showing the possible role of these animals as a reservoir.

B. valaisiana also infected our tick sample. This borrelia, occasionally detected in Lyme disease patients (Strle and Stanek 2009), is considered to be associated with avian species (Kurtenbach et al. 2002). Indeed, we detected it in over $80 \%$ I. ventalloi collected from the pheasant (Table 1, Figs. 1 and 2). Because pheasants have been shown to be reservoir hosts of B. valaisiana (Kurtenbach et al. 1998), it is possible that ticks were infected either during the blood meal on the examined 


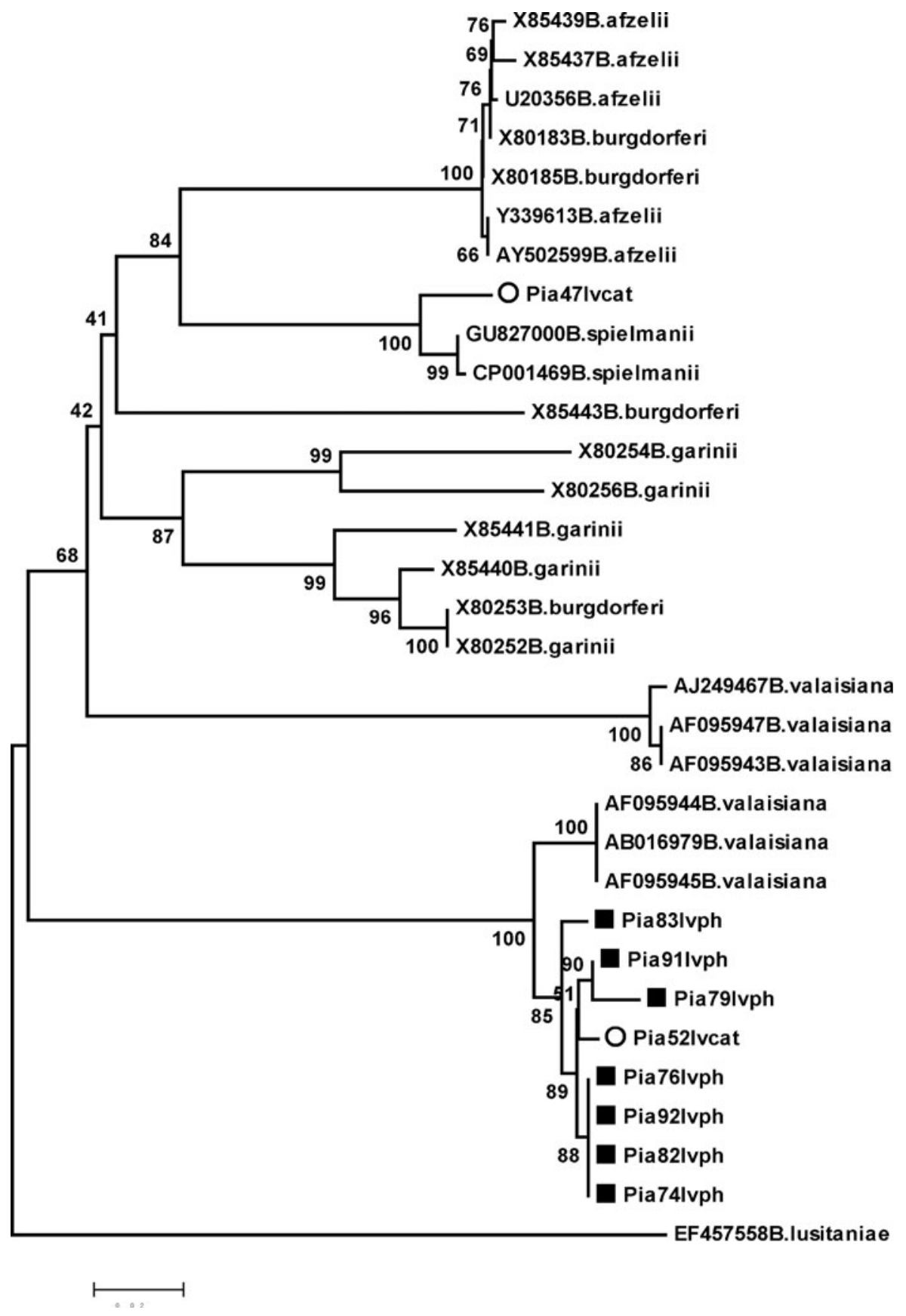

FIG. 2. Phylogenetic tree based on the OspA gene of Pianosa B. burgdorferi s.l. sequences and NCBI reference sequences. Pianosa sequences are highlighted by a square (positive ticks from pheasants) or a circle (positive ticks from cats). Iv, I. ventalloi; cat, tick collected on cat; ph, tick collected on pheasant. Posterior probability values are reported below branches. Bar, 0.02 substitutions per site.

host or on other pheasants in the previous tick stages. B. valaisiana was also detected in a I. ventalloi feeding on the water rail. This bird species was found infected by B. burgdorferi sensu stricto in a study in migrating birds in Slovakia (Schwarzová et al. 2006).

Apart from terrestrial birds, Ixodes ticks infected by borrelia were collected on felines. Cats, feral ones in particular, are exposed to B. burgdorferi s.l., but clinically apparent disease is not common. Their role as reservoir for this pathogen is unknown (Berrada and Telford 2009). Our results show a few positive ticks from cats $(8 \%)$, infected by B. spielmanii or B. valaisiana (Figs. 1 and 2), and we can thus hypothesize that these animals are not involved in the pathogen transmission in our study area.

The phylogenetic analysis of 5S-23S IGS showed the clusterization of Pianosa samples in the B. spielmanii or $B$. $v a-$ laisiana groups; no associations between genetic variability and unique ticks species or hosts were observed. Focusing on the $B$. valaisiana osp $A$ gene, this gene was conserved among our sequences. This may be due either to it being found in a 
single tick species, or to a geographic conservation in the island (Qiu et al. 2002). Indeed, only B. valaisiana subgroup I was identified in Pianosa. In other geographic areas, $B$. valaisiana subgroups I and II co-exist, such as in the regions at the France-Germany borders (Margos et al. 2009). A possible explanation of the presence of a unique subgroup in our study area may be the single migratory route, from Africa to northern Europe, passing on the Tuscany Archipelago through Tunisia.

Lyme spirochetes were detected in I. ventalloi and I. acuminatus. Recently, B. afzelii infection in I. acuminatus was reported in Hungary (Rigó et al. 2011), but this is the first finding of B. burgdorferi s.l. in I. ventalloi. Although B. burgdorferi s.l. has been detected or isolated from several ticks, Ixodes hexagonus and Ixodes uriae are the unique recognized alternative vectors besides I. ricinus (Gern et al. 2008). However, no other Ixodes spp. species were collected in Pianosa, so our results suggest the involvement of I. ventalloi and I. acuminatus in the B. burgdorferi s.l. biological cycle. The same tick species may be involved in SFG rickettsiae maintenance, because they were found to be infected by $R$. helvetica and Rickettsia sp. IRS3. Positive ticks were collected from terrestrial birds and cats; however, the role of vertebrate hosts in the transmission cycle of $R$. helvetica and other rickettsiae is not known, and ticks are considered reservoir and vectors of the pathogens (Boretti et al. 2009). Rickettsia spp. were already reported in I. ventalloi collected from migrating birds in Cyprus (Ioannou et al. 2009), Spain (Márquez 2008; Márquez and Millán 2009), and Portugal (Santos-Silva et al. 2006).

To the best of our knowledge, we report for the first time $R$. helvetica in I. acuminatus. Also R. helvetica is commonly associated with I. ricinus ticks, but according to Santos-Silva et al. (2006), the presence of this pathogen in alternative ticks could indicate the existence of secondary maintenance cycles. I. acuminatus is a parasite of small rodents, insectivores, and hedgehogs (Boyard et al. 2008; Rigó et al. 2011). The I. ventalloi life cycle depends on wild rabbits (Millán et al. 2007; Márquez 2008), but it was reported on carnivores, including cats, rodents, hedgehogs, and birds such as the partridge (Beichel et al. 1996; Santos-Silva et al. 2006, 2011; Ioannou et al. 2009). Because both Ixodes species are known to infest humans (Gilot and Marjolet, 1982), their possible role as zoonoses vectors can be speculated.

Likewise, Hyalomma ticks are well-known human parasites and can transmit a variety of diseases, including CrimeanCongo hemorrhagic fever (CCHF; Estrada-Peña and Jongejan 1999). Adults show an aggressive host-seeking behavior, and in our study area they were frequently found on the dragging operators' clothes. The small numbers of specimens obtained by dragging may be due to the limits of the method for collecting Hyalomma adults (Barandika et al. 2011). We detected $R$. aeschlimannii in host-seeking $H$. marginatum and H. detritum. This pathogen is characterized by a broad geographical distribution and is generally found in Hyalomma ticks from southern Europe (Croatia, Corsica, Cephalonia, Spain, Portugal, and Sicily; Beninati et al. 2005; Parola et al. 2005), North and sub-Saharan Africa (Beati et al. 1997; Mediannikov et al. 2010), and southwestern Russia (Shpynov et al. 2009). However, because of the long attachment on the hosts, Hyalomma immatures can be passively transported from the birds' wintering areas along migration routes (Jameson et al. 2012) and can spread rickettsiae to northern countries. For example,
R. aeschlimannii was recently detected in one $H$. marginatum from a bird migrating to Germany from Africa (Rumer et al. 2011).

In the light of the importance of the Tuscany Archipelago islands in the avian migratory routes, it would be interesting to clarify the role of avian species in the epidemiological cycles of both Lyme spirochetes and SFG rickettsiae in Pianosa. In fact, the involvement of wild birds in dispersing ticks and tickborne pathogens in Europe, and their role as reservoir hosts, are well established. Migrating birds may indeed contribute to the dispersal of ticks and tick pathogens from areas where their biological cycles are maintained, either acting as a reservoir or being responsible for pathogen transmission to species of the local fauna (Olsén et al. 1995, Santos-Silva et al. 2006, Elfving et al. 2010, Hildebrandt et al. 2010, Kjelland et al. 2010, Dietrich et al. 2011, Hasle et al. 2011, Vollmer et al. 2011, Jameson et al. 2012). Contacts between different bird species in seabird colonies and the presence of relatively generalist tick vectors may indeed provide opportunities for pathogen transmission between different enzootic systems (Dietrich et al. 2011). For example, the admixture between marine and terrestrial strains of $B$. garinii was recently demonstrated (Gómez-Díaz et al. 2011). The changes in climate and environment may facilitate the establishment in new areas of infected tick species transported by birds (Rumer et al. 2011), so the study of avian migration patterns, and of the agents infecting the ticks from migratory birds, may be very useful for the surveillance and control of emerging tick-borne zoonoses.

In conclusion, our survey showed the presence of emerging zoonotic agents in the B. burgdorferi s.l. complex and SFG rickettsiae in Pianosa and indicated the potential vectorial role of Hyalomma and Ixodes spp. ticks. These results highlight the risk of human exposure to Lyme disease and rickettsiosis in Pianosa, and tourists and workers visiting the island should pay attention to tick bites.

\section{Acknowledgments}

The authors thank the Direction of the Tuscan Archipelago National Park and personnel involved in the LIFE Nature Project LIFE04NAT/IT/000172, co-financed by EU Commission and Tuscany Regional Government (2004-2007).

\section{Author Disclosure Statement}

No competing financial interests exist.

\section{References}

Agnelli P. I mammiferi dell'isola di Pianosa. In: Museo Zoologico "La Specola" dell’Università degli Studi di Firenze (ed.). Studio tecnicoscientifico sull'Isola di Pianosa. Rapporto interno per l'Ente Parco Nazionale dell'Arcipelago Toscano. 1998: 48-50.

Akaike $\mathrm{H}$. Information theory and an extension of the maximum likelihood principle. Proceedings of the Second International Symposium on Information Theory Budapest: Akademiai Kiado Petrov BN, Csaki, 1973; 267-281.

Angelici FM, Laurenti A, Nappi A. A checklist of the mammals of small Italian islands. Hystrix It J Mamm 2009; 20:3-27.

Barandika JF, SA Olmeda, MA Casado-Nistal et al. Differences in questing tick species distribution between Atlantic and continental climate regions in Spain. J Med Entomol 2011; 48:13-19. 
Beati L, Meskini M, Thiers B, Raoult D. Rickettsia aeschlimannii sp. nov., a new spotted fever group rickettsia associated with Hyalomma marginatum ticks. Int J Syst Bacteriol 1997; 47: 548-554.

Beichel E, Petney TN, Hassler D, Brückner M, Maiwald M. Tick infestation patterns and prevalence of Borrelia burgdorferi in ticks collected at a veterinary clinic in Germany. Vet Parasitol 1996; 65:147-155.

Beninati T, Genchi C, Torina A, Caracappa S, et al. Rickettsiae in ixodid ticks, Sicily. Emerg Infect Dis 2005; 11:509-511.

Berrada ZL, Telford SR. Burden of tick-borne infections on American companion animals. Top Companion Anim Med 2009; 24:175-181.

Boyard C, Vourc'h G, Barnouin J. The relationships between Ixodes ricinus and small mammal species at the woodlandpasture interface. Exp Appl Acarol 2008; 44:61-76.

Boretti FS, Perreten A, Meli ML, Cattori V, et al. Molecular Investigations of Rickettsia helvetica infection in dogs, foxes, humans, and Ixodes ticks. Appl Environ Microbiol 2009; 75: 3230-3237.

Colom MR, Vaccari FP, Scartazza A, Brugnoli E, et al. Pianosa island: Structure, functioning and biodiversity of main ecosystems. J Med Ecol 2004; 5:31-40.

Cringoli G, Iori A, Rinaldi L, Veneziano V, Genchi C. Zecche. Mappe Parassitologiche. Napoli: Rolando Editore, 2005:308 pp.

Dietrich M, Gómez-Díaz E, McCoy KD. Worldwide distribution and diversity of seabird ticks: implications for the ecology and epidemiology of tick-borne pathogens. Vector Borne Zoonotic Dis $2011 ; 11: 453-470$.

Elfving K, Olsén B, Bergström S, Waldenström J, et al. Dissemination of spotted fever rickettsia agents in Europe by migrating birds. PLoS One 2010; 5:e8572

Estrada-Peña A, Jongejan F. Ticks feeding on humans: A review of records on human-biting Ixodoidea with special reference to pathogen transmission. Exp Appl Acarol 1999; 23:685-715.

Estrada-Peña A, Bouattour A, Camicas JL, Walker AR. Ticks of Domestic Animals in the Mediterranean Region. Ed. University of Zaragoza; 2004:131 pp.

Fingerle V, Schulte-Spechtel UC, Ruzic-Sabljic E, Leonhard S, et al. Epidemiological aspects and molecular characterization of Borrelia burgdorferi s.l. from southern Germany with special respect to the new species Borrelia spielmanii sp. nov. Int J Med Microbiol 2008; 298:279-290.

Gern L. Borrelia burgdorferi sensu lato, the agent of Lyme borreliosis: Life in the wilds. Parasite 2008; 15: 244-247.

Gilot B, Marjolet M. Contribution à l'étude du parasitisme humain par les tiques (Ixodidae et Argasidae), plus particulierement dans le sud-est de la France. Méd Maladies Infect 12:340-351.

Grego E, Bertolotti L, Peletto S, Amore G, et al. Borrelia lusitaniae OspA gene heterogeneity in Mediterranean basin area. J Mol Evol 2007; 65:512-24518.

Gómez-Díaz E, Boulinier T, Sertour N, Cornet M, et al. Genetic structure of marine Borrelia garinii and population admixture with the terrestrial cycle of Lyme borreliosis. Environ Microbiol 2011; 13:2453-2467.

Hasle G, Bjune GA, Midthjell L, Røed KH, Leinaas HP. Transport of Ixodes ricinus infected with Borrelia species to Norway by northward-migrating passerine birds. Ticks Tick Borne Dis 2011; 2:37-43.

Hildebrandt A, Franke J, Meier F, Sachse S, et al. The potential role of migratory birds in transmission cycles of Babesia spp., Anaplasma phagocytophilum, and Rickettsia spp. Ticks Tick Borne Dis 2010; 1:105-107.
Ioannou I, Chochlakis D, Kasinis N, Anayiotos P, et al. Carriage of Rickettsia spp., Coxiella burnetii and Anaplasma spp. by endemic and migratory wild birds and their ectoparasites in Cyprus. Clin Microbiol Infect 2009; 15:158-160.

Jameson LJ, Morgan PJ, Medlock JM, Watola G, Vaux AG. Importation of Hyalomma marginatum, vector of Crimean-Congo haemorrhagic fever virus, into the United Kingdom by migratory birds. Ticks Tick Borne Dis 2012 [Epub ahead of print].

Kjelland V, Stuen S, Skarpaas T, Slettan A. Borrelia burgdorferi sensu lato in Ixodes ricinus ticks collected from migratory birds in Southern Norway. Acta Vet Scand 2010; 6:52-59.

Kurtenbach K, Peacey M, Rijpkema SGT, Hoodless AN, et al. Differential transmission of the genospecies of Borrelia burgdorferi sensu lato by game birds and small rodents in England. Appl Environ Microbiol 1998; 64:1169-1174.

Kurtenbach K, De Michelis S, Etti S, Schafer SM, et al. Host association of Borrelia burgdorferi sensu lato-the key role of host complement. Trends Microbiol 2002; 10:74-79.

Labruna MB, Mattar S, Nava S, Bermudez S, et al. Rickettsioses in Latin America, Caribbean, Spain and Portugal. Rev MVZ Córdoba 2011; 16:2435-2457

LIFE04NAT/IT/000172 Progetto Life Natura "Isole di Toscana: Nuove azioni per uccelli marini e habitat". Available at http:// ec.europa.eu/environment/life/project/Projects/index.cfm? fuseaction $=$ home. showFile\&rep $=$ laymanReport\&fil = LIFE04 NAT_IT_000172_LAYMAN.pdf/. Accessed October 31, 2012.

Manilla G. Acari, Ixodida (Fauna d'Italia 36). Bologna, Italy; Edizioni Calderoni, 1998.

Margos G, Vollmer SA, Cornet M, Garnier M, et al. A new Borrelia species defined by multilocus sequence analysis of housekeeping genes. Appl Environ Microbiol 2009; 75:54105416.

Márquez FJ. Spotted fever group Rickettsia in ticks from southeastern Spain natural parks. Exp Appl Acarol 2008; 45: 185-194.

Márquez FJ, Millán J. Rickettsiae in ticks from wild and domestic carnivores of Doñana National Park (Spain) and surrounding area. Clin Microbiol Infect 2009; 15:224-226.

Matsumoto K, Parola P, Brouqui P, Raoult D. Rickettsia aeschlimannii in Hyalomma ticks from Corsica. Eur J Clin Microbiol Infect Dis 2004; 23:732-734.

Mediannikov O, Diatta G, Fenollar F, Sokhna C, Trape JF, Raoult D. Tick-borne rickettsioses, neglected emerging diseases in rural Senegal. PLoS Negl Trop Dis 2010; 4:pii e821.

Millán J, Ruiz-Fons F, Márquez FJ, Viota M, et al. Ectoparasites of the endangered Iberian lynx Lynx pardinus and sympatric wild and domestic carnivores in Spain. Med Vet Entomol 2007; 21:248-254.

Nei M, Gojobori T. Simple methods for estimating the numbers of synonymous and nonsynonymous nucleotide substitutions. Mol Biol Evol 1986; 3:418-426.

Olsén B, Jaenson TG, Bergström S. Prevalence of Borrelia burgdorferi sensu lato-infected ticks on migrating birds. Appl Environ Microbiol 1995; 61:3082-3087.

Parola P, Paddock CD, Raoult D. Tick-borne rickettsiosis around the world: Emerging diseases challenging old concepts. Clin Microbiol Rev 2005; 18:719-756.

Posada D, Crandall KA. Selecting the best-fit model of nucleotide substitution. Syst Biol 2001; 50:580-601.

Qiu WG, Dykhuizen DE, Acosta MS, Luft BJ. Geographic uniformity of the Lyme disease spirochete (Borrelia burgdorferi) and its shared history with tick vector (Ixodes scapularis) in the Northeastern United States. Genetics 2002; 160: 833-849. 
R Development Core Team. R: A language and environment for statistical computing. 2008. Available at www.R-project.org/.

Richter D, Schlee DB, Allgöwer R, Matuschka FR. Relationships of a novel Lyme disease spirochete, Borrelia spielmani sp. nov., with its hosts in Central Europe. Appl Environ Microbiol 2004; 70:6414-6419.

Richter D, Schlee DB, Matuschka FR. Reservoir competence of various rodents for the Lyme disease spirochete Borrelia spielmanii. Appl Environ Microbiol 2011; 77:3565-3570.

Rigó K, Gyuranecz M, Tóth AG, Földvári G. Detection of Borrelia burgdorferi sensu lato and Anaplasma phagocytophilum in small mammals and ectoparasites in Hungary. Vector Borne Zoonotic Dis 2011; 11:1499-1501.

Rijpkema SG, Molkenboer MJ, Schouls LM, Jongejan F, Schellekens JF. Simultaneous detection and genotyping of three genomic groups of Borrelia burgdorferi sensu lato in Dutch Ixodes ricinus ticks by characterization of the amplified intergenic spacer region between $5 \mathrm{~S}$ and $23 \mathrm{~S}$ rRNA genes. J Clin Microbiol 1995; 33:3091-3095.

Ronquist F, Huelsenbeck JP. MrBayes 3: Bayesian phylogenetic inference under mixed models. Bioinformatics 2003; 19:15721574.

Rumer L, Graser E, Hillebrand T, Talaska T, et al. Rickettsia aeschlimannii in Hyalomma marginatum ticks, Germany. Emerg Infect Dis 2011; 17:325-326.

Ryffel K, Péter O, Dayer E, Bretz AG, Godfroid E. OspA heterogeneity of Borrelia valaisiana confirmed by phenotypic and genotypic analyses. BMC Infect Dis 2003; 3:14.

Santos-Silva MM, Sousa R, Santos AS, Melo P, et al. Ticks parasitizing wild birds in Portugal: detection of Rickettsia aeschlimannii, R. helvetica and R. massiliae. Exp Appl Acarol 2006; 39:331-338.

Santos-Silva MM, Beati L, Santos AS, De Sousa R, et al. The hard-tick fauna of mainland Portugal (Acari: Ixodidae): an update on geographical distribution and known associations with hosts and pathogens. Exp Appl Acarol 2011; 55:85-121.

Schwarzová K, Betáková T, Neméth J, Mizáková A. Detection of Borrelia burgdorferi sensu lato and Chlamydophila psittaci in throat and cloacal swabs from birds migrating through Slovakia. Folia Microbiol (Praha) 2006; 51:653-658.
Shpynov S, Rudakov N, Tohkov Y, Matushchenko A, et al. Detection of Rickettsia aeschlimannii in Hyalomma marginatum ticks in western Russia. Clin Microbiol Infect 2009; 15:315-316.

Skuballa J, Oehme R, Hartelt K, Petney T, et al. European hedgehogs as hosts for Borrelia spp., Germany. Emerg Infect Dis 2007; 13:952-953.

Skuballa J, Petney T, Pfäffle M, Oehme R, et al. Occurrence of different Borrelia burgdorferi sensu lato genospecies including B. afzelii, B. bavariensis, and B. spielmanii in hedgehogs (Erinaceus spp.) in Europe. Ticks Tick Borne Dis 2012; 3:8-13

Stanek G, Reiter M. The expanding Lyme Borrelia complexclinical significance of genomic species? Clin Microbiol Infect 2011; 17:487-493.

Strle F, Stanek G. Clinical manifestations and diagnosis of Lyme borreliosis. Curr Probl Dermatol 2009; 37:51-110.

Swofford D. PAUP*: Phylogenetic analysis using parsimony (*and other methods), ver.4.0. Sunderland, MA, Sinauer Associates. 2003. Available at http://paup.csit.fsu.edu/index.html/.

Thompson JD, Gibson TJ, Plewniak F, Jeanmougin F, Higgins DG. The CLUSTAL $X$ windows interface: Flexible strategies for multiple sequence alignment aided by quality analysis tools. Nucleic Acids Res 1997; 25:4876-4882.

Tomassone L, Conte V, Parrilla G, De Meneghi D. Rickettsia infection in dogs and Rickettsia parkeri in Amblyomma tigrinum ticks, Cochabamba Department, Bolivia. Vector Borne Zoonotic Dis 2010; 10:953-958.

Vollmer SA, Bormane A, Dinnis RE, Seelig F, et al. Host migration impacts on the phylogeography of Lyme Borreliosis spirochaete species in Europe. Environ Microbiol 2011; 13:184-192.

Wang G, van Dam AP, Dankert J. Two distinct ospA genes among Borrelia valaisiana strains. Res Microbiol 2000; 151:325-331.

Address correspondence to: Laura Tomassone Dipartimento di Produzioni Animal, Epidemiologia ed Ecologia Universita di Torino Via L. Da Vinci 44 10095 Grugliasco Italy

E-mail: laura.tomassone@unito.it 